\title{
Microstructure and Mechanical Properties of the As-Cast and Extruded Mg-(6-11)Li-3Al-Ce-Ca Alloys
}

\author{
Liren Cheng $^{1}$, Zhanyi Cao ${ }^{1, *}$, Ruizhi $\mathrm{Wu}^{2}$, Milin $\mathrm{Zhang}^{2}$ and Dongmei Jiang ${ }^{3}$ \\ ${ }^{1}$ Key Laboratory of Automobile Materials of Ministry of Education, Department of Education, \\ Department of Materials Science \& Engineering, Jilin University, \\ No. 5988 Renmin Street, Changchun 130025, P. R. China \\ ${ }^{2}$ Key Laboratory of Superlight Materials \& Surface Technology (Harbin Engineering University), \\ Ministry of Education, Harbin 150001, P. R. China \\ ${ }^{3}$ Mechanics Teaching and Research Office, Aviation University of Air Force, \\ No. 7855 Renmin Street, Changchun 130022, P. R. China
}

Samples of (A) Mg-6.86Li-3.02Al-1.12Ce-0.7Ca, (B) Mg-8.15Li-3.07Al-1.12Ce-0.72Ca and (C) Mg-10.54Li-3.54Al-1.23Ce-0.94Ca alloys are prepared by casting and extrusion process. The microstructure and mechanical properties of alloys are characterized. The results indicate that the as-cast specimens of (A) and (B) have $\alpha+\beta$ dual phase structure and the as-cast (C) alloy has $\beta$ phase (Li), $\alpha+\beta$ eutectic structure. Bulk and rod-like $\mathrm{Al}_{2} \mathrm{Ce}$ and $\mathrm{Al}_{2} \mathrm{Ca}$ compounds are found in matrix and boundaries in all the alloys. The orientation relationship

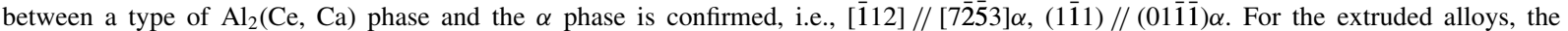
microstructures are refined and the $\beta$ phase has the effect of coordination during deformation. The long rod-like and bulk compounds become short rods and fine clumps distributing evenly in the extruding direction. The microstructure of extruded Mg-10.54Li-3.54Al-1.23Ce-0.94-Ca alloy testifies the existence of the eutectic structure. The tensile strength and yield strength of Mg-6.86Li-3.02Al-1.12Ce-0.7Ca (UTS: $12.5 \%$, YS: $36 \%$ ) and Mg-8.15Li-3.07-Al-1.12Ce-0.72Ca (UTS: 24\%, YS: 46\%) alloys have improved after extruding process.

[doi:10.2320/matertrans.M2010156]

(Received April 30, 2010; Accepted June 14, 2010; Published August 25, 2010)

Keywords: magnesium-lithium alloys, extrusion, mechanical properties

\section{Introduction}

Magnesium-lithium (Mg-Li) alloys are known as one of the lightest materials and attracting much attention, not only due to their ultra-low density, but also for the reason that addition of lithium to magnesium giving rise to highly workable, body-centred cubic alloys. ${ }^{1,2)} \mathrm{Mg}$-Li alloys containing $6-11 \%$ mass\% Li exhibit two phase strucrures consisting of the $\alpha$-magnesium rich (hcp) and $\beta$-lithium rich (bcc) phases. The body centered cubic $\beta$ phase is soft and ductile. Hence, the double phases $\mathrm{Mg}-\mathrm{Li}$ alloys usually have better comprehensive mechanical properties than single phase $(\alpha$ or $\beta){ }^{3,4)}$

Much effort has been made to improve the application performance. For example, to develop creep resistant $\mathrm{Mg}-\mathrm{Li}$ alloys, the existence of the intermetallic compound with a high thermal stability at grain boundaries and inside grains is necessary. The intermetallics distributed inside the grains can pin the dislocations during creep deformation. The rare earth additions can improve the thermal stability and the mechanical properties of $\mathrm{Mg}$-Li alloys. ${ }^{5,6)}$ Calcium has potential to further reduce the density of $\mathrm{Mg}-\mathrm{Li}$ alloys and, with its limited solid solubility, to provide strength through forming a second phase(s), to inhibit the ignition of molten magnesium and to reduce solid oxidation of $\mathrm{Mg}$-Li alloys. ${ }^{7-9)}$ Mixed $\mathrm{RE}$ elements and $\mathrm{Ca}$ in the AZ91 Alloys can not only improve the ultimate tensile strength, but also improve the corrosion resistance due to the formation of the reticular $\mathrm{Al}_{2} \mathrm{Ca}$ phase which acted as an effective barrier against corrosion. ${ }^{10,11)}$

${ }^{*}$ Corresponding author, E-mail: zycao@jlu.edu.cn
The aim of present work was to study the interaction of $\mathrm{Ca}$ and $\mathrm{Ce}$ elements with addition of $\mathrm{Al}$ element on the microstructure and mechanical properties of different lithium content dual phase Mg-Li alloys. The strength effect of extruding process is estimated. Compounds with different appearances have been conformed by TEM research method.

\section{Experimental Procedure}

The materials used in the experiment are commercial pure (CP) magnesium ingot, $\mathrm{CP}$ lithium, $\mathrm{CP}$ aluminum, $\mathrm{Mg}$-26Ce and $\mathrm{Mg}-50 \mathrm{Ca}$ master-alloys. The charging materials were melted in vacuum melting furnace with argon atmosphere. The nominal chemical compositions of alloys prepared in experiments were: (A) Mg-6.86Li-3.02Al-1.12Ce-0.7Ca, (B) $\mathrm{Mg}-8.15 \mathrm{Li}-3.07 \mathrm{Al}-1.12 \mathrm{Ce}-0.72 \mathrm{Ca}$ and (C) $\mathrm{Mg}-10.54 \mathrm{Li}-$ 3.54Al-1.23Ce-0.94Ca. Then the as-cast specimens were annealed at $573 \mathrm{~K} \times 12 \mathrm{~h}$ for the forthcoming deformation process. After heat treatment, the specimens were extruded at $493 \mathrm{~K}$ from $\Phi 50 \mathrm{~mm}$ to $\Phi 14 \mathrm{~mm}$ with a constant speed of $2.0 \mathrm{~m} / \mathrm{min}$.

Chemical composition of the cast alloys were detected by induction coupled plasma (ICP) apparatus X Series II ICPMS and test results are shown in Table 1. Microstructures of specimens were observed with a combination of Olympus OLS 3000 scanned-laser microscope, scanning electron microscopy (SEM) with energy dispersive spectroscopy (EDS), high-resolution transmission electron microscope (HR-TEM, JEM-2100F) with $200 \mathrm{KV}$, and X-ray diffraction (XRD, Rigaku D/max-2550).

Tensile test was carried out with the strain rate of $5 \times 10^{-4} \mathrm{~S}^{-1}$ using a universal testing machine (MTS-810, 
Table 1 The ICP test results.

\begin{tabular}{cccccc}
\hline \multirow{2}{*}{ Invariant alloys } & \multicolumn{5}{c}{ Element compositions } \\
\cline { 2 - 6 } & $\begin{array}{c}\text { mass\% } \\
\mathrm{Li}\end{array}$ & $\begin{array}{c}\text { mass\% } \\
\mathrm{Al}\end{array}$ & $\begin{array}{c}\text { mass\% } \\
\mathrm{Ca}\end{array}$ & $\begin{array}{c}\text { mass\% } \\
\mathrm{Ce}\end{array}$ & $\begin{array}{c}\text { mass\% } \\
\mathrm{Mg}\end{array}$ \\
\hline $\mathrm{Mg}-8 \mathrm{Li}-3 \mathrm{Al}-1 \mathrm{Ce}-1 \mathrm{Ca}$ & 6.86 & 3.02 & 0.70 & 1.12 & Bal. \\
\hline $\mathrm{Mg}-10 \mathrm{Li}-3 \mathrm{Al}-1 \mathrm{Ce}-1 \mathrm{Ca}$ & 8.15 & 3.07 & 0.72 & 1.25 & Bal. \\
\hline $\mathrm{Mg}-12 \mathrm{Li}-3 \mathrm{Al}-1 \mathrm{Ce}-1 \mathrm{Ca}$ & 10.54 & 3.54 & 0.94 & 1.23 & Bal. \\
\hline
\end{tabular}

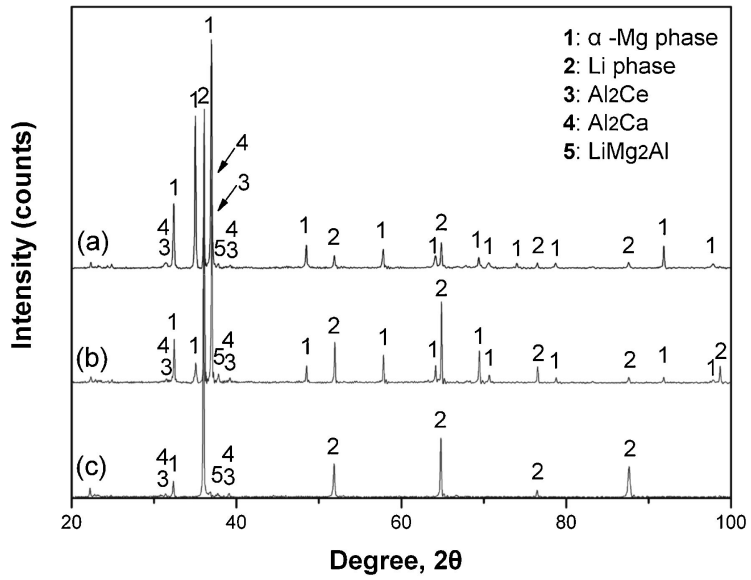

Fig. 1 XRD results of as-cast $\mathrm{Mg}-\mathrm{Li}$ alloys: (a) $\mathrm{Mg}-8 \mathrm{Li}-3 \mathrm{Al}-1 \mathrm{Ce}-1 \mathrm{Ca}$ (b) $\mathrm{Mg}-12 \mathrm{Li}-3 \mathrm{Al}-1 \mathrm{Ce}-1 \mathrm{Ca}$.

USA). The fracture surfaces were examined using SEM. In the tensile tests, plate-type dimensions were designed according to the standard of ASTM E M8-08 (plate-type: $4 \mathrm{~mm}$ of width).

\section{Results and Discussion}

\subsection{Analysis of the as-cast structure}

Figure 1 shows XRD patterns from all the three as-cast alloys. The patterns (a) and (b) (Mg-6.86Li-3.02Al-1.12Ce$0.7 \mathrm{Ca}$ and $\mathrm{Mg}-8.15 \mathrm{Li}-3.07 \mathrm{Al}-1.12 \mathrm{Ce}-0.72 \mathrm{Ca}$ respectively) show that small peaks of $\mathrm{Al}_{2} \mathrm{Ce}$ and $\mathrm{Al}_{2} \mathrm{Ca}$ intermetallic phases are identifiable, strongly indicating the presence of a small amount of the dispersed. On the other hand, the pattern (c) $(\mathrm{Mg}-10.54 \mathrm{Li}-3.54 \mathrm{Al}-1.23 \mathrm{Ce}-0.94 \mathrm{Ca})$ shows only both the bcc crystal structure (Li) and hcp crystal structure $(\mathrm{Mg})$, which is in agreement with eutectic constituents occurring in the $\mathrm{Mg}$-Li binary phase diagram. Local intensity of $\mathrm{Al}_{2} \mathrm{Ce}$ and $\mathrm{Al}_{2} \mathrm{Ca}$ peaks is too low to present themselves comparing with $\beta$ (Li) peaks in Fig. 1(b).

Early studies ${ }^{12}$ ) have shown that $\mathrm{Mg}-6.86 \mathrm{Li}-3.02 \mathrm{Al}-$ $1.12 \mathrm{Ce}-0.7 \mathrm{Ca}$ and $\mathrm{Mg}-8.15 \mathrm{Li}-3.07 \mathrm{Al}-1.12 \mathrm{Ce}-0.72 \mathrm{Ca}$ alloys exhibit distinct micro-constituents besides the compounds that precipitated from matrix: $\alpha(\mathrm{Mg})$ phase and $\beta(\mathrm{Li})$ phase regions. The relative amount of $\beta$ (Li) phase region increases as the Li-content increases and the eutectic reaction occurred when the Li-content reaches to 12 mass $\%$. Much of the precipitated compounds are located at the grain boundaries in the $\mathrm{Mg}-6.86 \mathrm{Li}-3.02 \mathrm{Al}-1.12 \mathrm{Ce}-0.7 \mathrm{Ca}$ and $\mathrm{Mg}-8.15-\mathrm{Li}-$ 3.07 Al-1.12Ce-0.72Ca alloys.

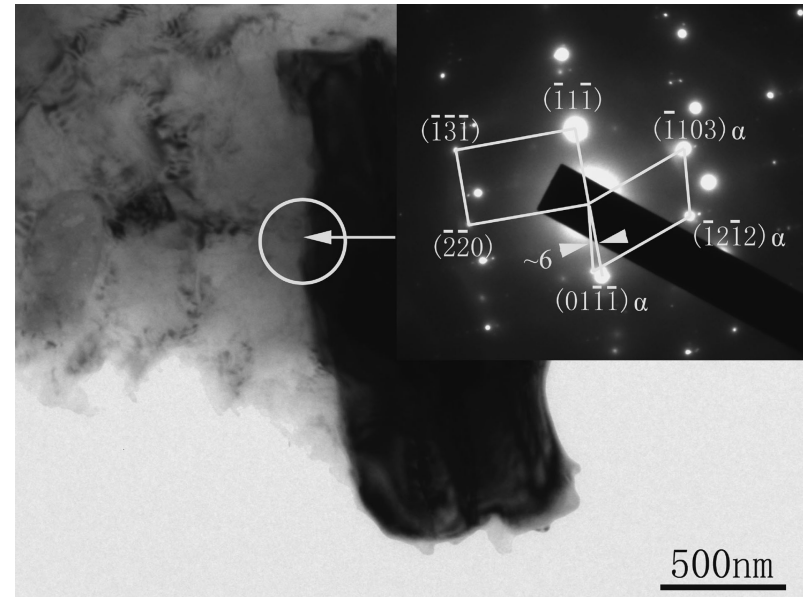

Fig. 2 TEM analyses of the precipitated compound in as-cast $\mathrm{Mg}-10 \mathrm{Li}$ 3Al-1Ce-1Ca specimen.

According to EDS and XRD analysis result in the preresearch work, $\mathrm{Al}_{2}(\mathrm{Ce}, \mathrm{Ca})$ compound had been also confirmed. ${ }^{12)}$ This kind of precipitated compound is composed of $\mathrm{Al}, \mathrm{Ce}, \mathrm{Ca}$ elements and has the same cubic crystal structure with the $\mathrm{Al}_{2} \mathrm{Ca}$ compound. Selected area diffraction patterns (SADP) taken with CLD aperture placed across a planer interface between the $\alpha$ matrix and the $\mathrm{Al}_{2}(\mathrm{Ce}, \mathrm{Ca})$ compound (see Fig. 2), show that the orientation relationship is: $[\overline{1} 12] / /[\overline{7} \overline{2} \overline{5} 3] \alpha,(1 \overline{1} 1) / /(01 \overline{1} \overline{1}) \alpha$. However, the pattern is not well centered for both phases simultaneously, indicating that $[\overline{1} 12]$ and $[7 \overline{2} \overline{5} 3] \alpha$ directions are not exactly parallel. Similar orientation relationship is calculated by M. V. Kral, etc. ${ }^{13)}$ in study of the crystallography of Mg-8Li alloy. An addition $\sim 6^{\circ}$ rotation of the fcc lattice around $[\overline{1} 12] / /[\overline{7} \overline{5} 3] \alpha$ is observed. This means that there should be a continuum of these rigid body rotations of the close packed planes about the principle axis from $0^{\circ}$ to $6^{\circ}$. The above results indicate that the existence of the $\mathrm{Al}_{2}(\mathrm{Ce}, \mathrm{Ca})$ brings much lattice distortion and enhances the alloy strength.

The dispersion of electronegativity values between magnesium (1.31) and calcium (1.0) is less than that between aluminum (1.61) and calcium. However, for the reasons of non-equilibrium solidification and elements segregation, a $\mathrm{Mg}_{2} \mathrm{Ca}$ compound is observed along the grain boundary, as shown in Fig. 3. The diffraction pattern of the magnesium matrix (hcp) and $\mathrm{Mg}_{2} \mathrm{Ca}$ (hcp) compound are marked respectively.

\subsection{Analysis of the extruded structure}

The extruded structures of all the three alloys exhibit fibrous extruding texture, which are typical plastically deformed structures (see Fig. 4). As a soft phase in matrix, $\beta$ (Li) phase become a mediate of coordinating deformation. It is known that the shape of $\beta$ (Li) phase becomes long strip under the compression stress in the extruding direction. The bulk and rod-like compounds break up into short rods or fine clumps and distribute evenly in matrix. Because of different formability between the $\alpha(\mathrm{Mg})$ phase and $\beta$ (Li) phase, it is clear that $\alpha(\mathrm{Mg})$ phase show up and assemble in the form of white long strip along the extruding direction, 


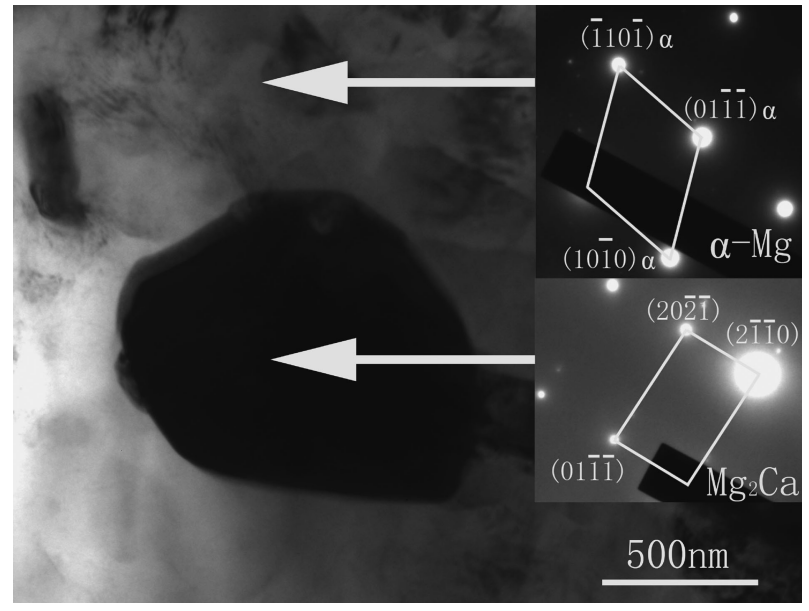

Fig. 3 TEM analyses of the $\mathrm{Mg} 2 \mathrm{Ca}$ compound along the grain boundary in as-cast Mg-10Li-3Al-1Ce-1Ca0.94 specimen.

which the eutectic structure can not be seen in the as-cast Mg-10.54Li-3.54Al-1.23Ce-0.94Ca alloy. Moreover, experimental studies ${ }^{14)}$ show that the average content of $\beta$ phase will decrease during superplastic deformation. This is another reason for the presence of the $\alpha$ phase in the $\mathrm{Mg}$ 10.54Li-3.54Al-1.23Ce-0.94Ca alloy.

Hcp crystal structure precipitation in $\beta$ lithium matrix is observed in the $\mathrm{Mg}-8.15 \mathrm{Li}-3.07 \mathrm{Al}-1.12 \mathrm{Ce}-0.72 \mathrm{Ca}$, as illustrated in Fig. 5. EDS analysis indicates that only the $\mathrm{Mg}$ and $\mathrm{Al}$ elements are present in the dark region. Regardless the factor of Al solid solution in both magnesium matrix and lithium matrix, the result suggests that the hcp crystal structure precipitation should be magnesium phase.

Figure 6 demonstrates the detail microstructure of the extruded Mg-8.15Li-3.07-Al-1.12Ce-0.72Ca alloy. $\mathrm{Al}_{2}(\mathrm{Ce}$, $\mathrm{Ca}$ ) compound clearly appears, according to the results of EDS analysis and SADP in Fig. 6(a). For the reason of lattice distortion, stacking fault density decreases at the vicinity of compounds as compared with the matrix region. The Fig. 6(b) should be HR-TEM micrograph of (0110) $\alpha$ crystal plane in magnesium matrix, the strip of dark region is the stacking fault according to $\{0001\}\langle 11 \overline{2} 0\rangle$ slip system. Much information about the crystal structure can be concluded from Fourier transformation showed in Fig. 6(b).

It is well known that addition of Li may result in higher activity of non-basal slip. Cross-slip and climb of dislocations may be responsible for the softening in the hightemperature plastic deformation process, especially for the single-phase $\mathrm{Mg}$-Li alloy. ${ }^{15)}$ However, during deformation of dual phase $\mathrm{Mg}$ - Li alloy polycrystals, another factor of codeformation between $\alpha$ and $\beta$ phases is assumed. The $\{0001\}\langle 11 \overline{2} 0\rangle$ slip system in the $\alpha$ phase and $\{110\}\langle 111\rangle$ slip system in the $\beta$ phase can match with each other, according to the calculation of crystallography of the bcc/hcp transformation in the $\mathrm{Mg}$-Li alloy that had been reported. ${ }^{13)}$ This means that screw components of the basal dislocations in $\alpha$ phase can move to adjacent slip plane in $\beta$ phase at the appropriate stress state. Therefore, the free path of dislocations increases, especially at high temperature. The stacking fault in Fig. 6(a) may be the circumstantial evidence of codeformation instead of cross-slip.
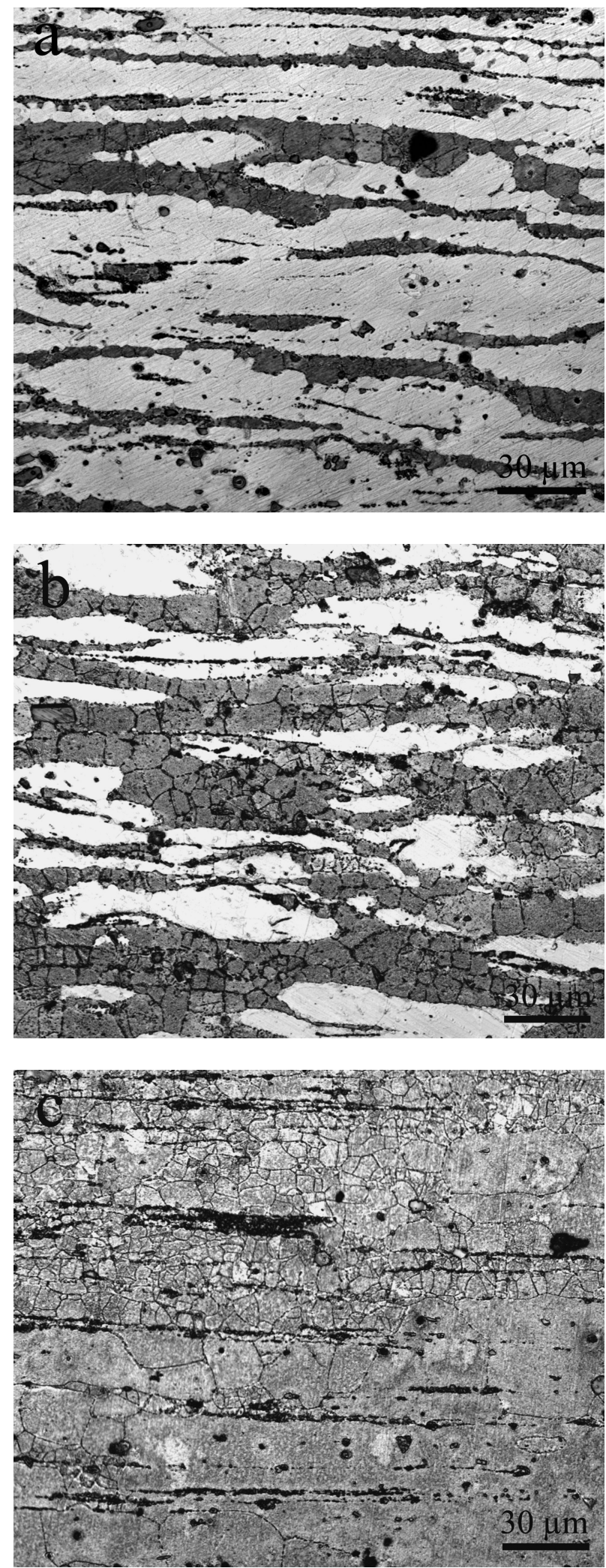

Fig. 4 Scanned-laser microscope micrographs showing microstructures evolution in the extruded $\mathrm{Mg}$-Li alloys with different levels of $\mathrm{Li}$ that parallel to the extruding direction: (a) Mg-8Li-3Al-1Ce-1Ca, (b) Mg-10Li$3 \mathrm{Al}-1 \mathrm{Ce}-1 \mathrm{Ca}$ and (c) $\mathrm{Mg}-12 \mathrm{Li}-3 \mathrm{Al}-1 \mathrm{Ce}-1 \mathrm{Ca}$.

\subsection{Analysis of mechanical properties}

Figures 7(a) and (b) show the recorded engineering stressstrain curves of the as-cast and extruded alloys during tension under a constant strain rate of $0.5 \times 10^{-3} \mathrm{~S}^{-1}$ respectively. 


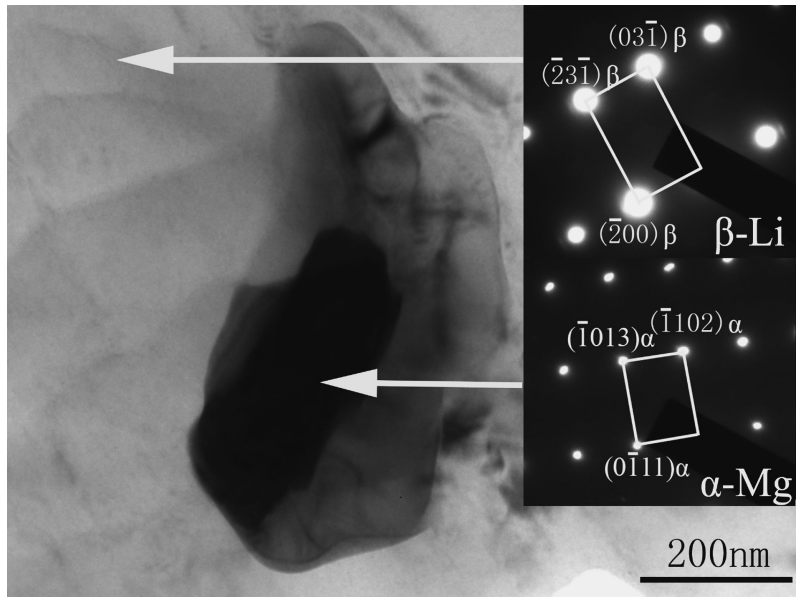

Fig. 5 TEM analyses of the extruded Mg-10Li-3Al-1Ce-1Ca alloy.
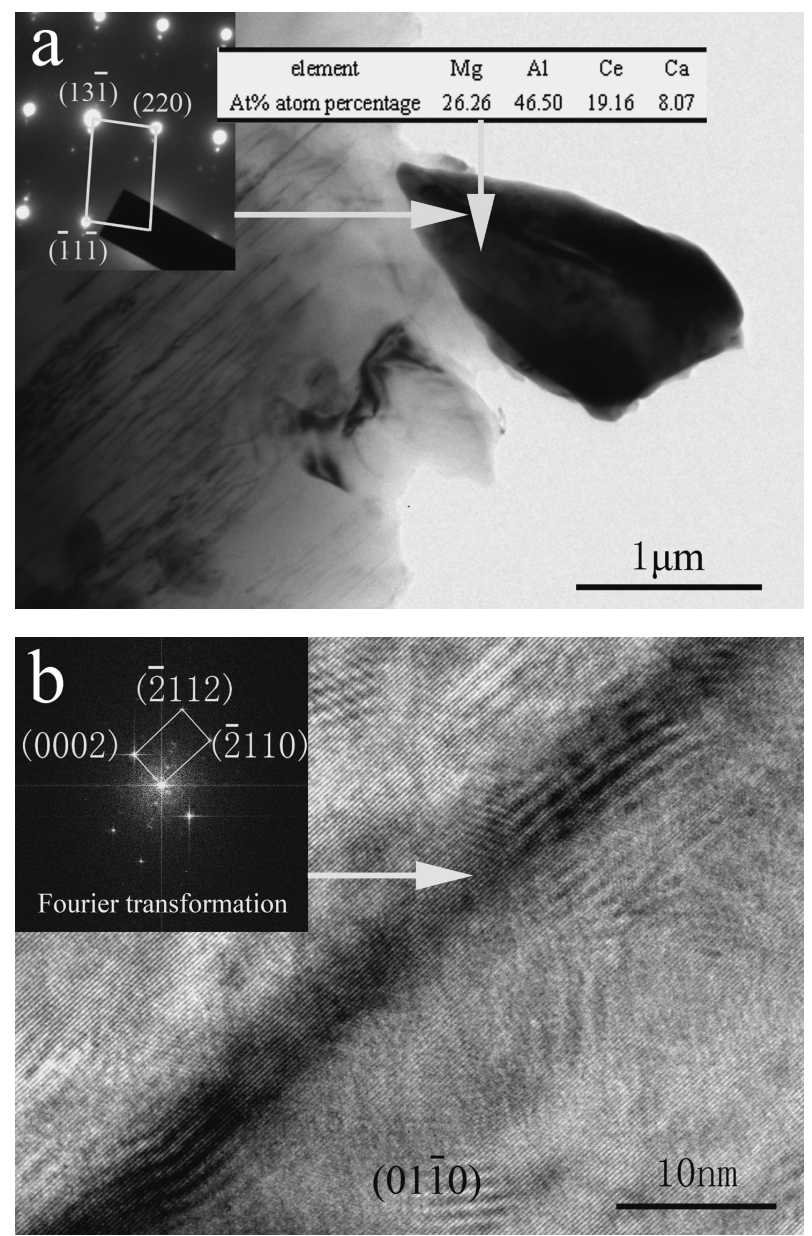

Fig. 6 Microstructures of the extruded $\mathrm{Mg}-10 \mathrm{Li}-3 \mathrm{Al}-1 \mathrm{Ce}-1 \mathrm{Ca}$ alloy with a $\mathrm{Al}_{2}(\mathrm{Ce}, \mathrm{Ca})$ compound: (a) TEM image and SADP of the $\mathrm{Al}_{2}(\mathrm{Ce}, \mathrm{Ca})$ compound and (b) HR-TEM image and Fourier transformation of the deformation region in magnesium matrix in image (a).

For the as-cast specimens, with the $\mathrm{Li}$ addition rising from 6.86 mass $\%$ to 10.54 mass $\%$, the yield strength (YS) improve by $36 \%$ and the ultimate tensile strength (UTS) decrease by $17.6 \%$ (Fig. 7(a)). The Mg-8.15Li-3.07Al-1.12Ce-0.72Ca alloy presents the highest elongation $(28 \%)$ than the other two. It becomes very clear that the tensile strength and yield strength of Mg-6.86Li-3.02Al-1.12Ce-0.7Ca (UTS: $12.5 \%$,
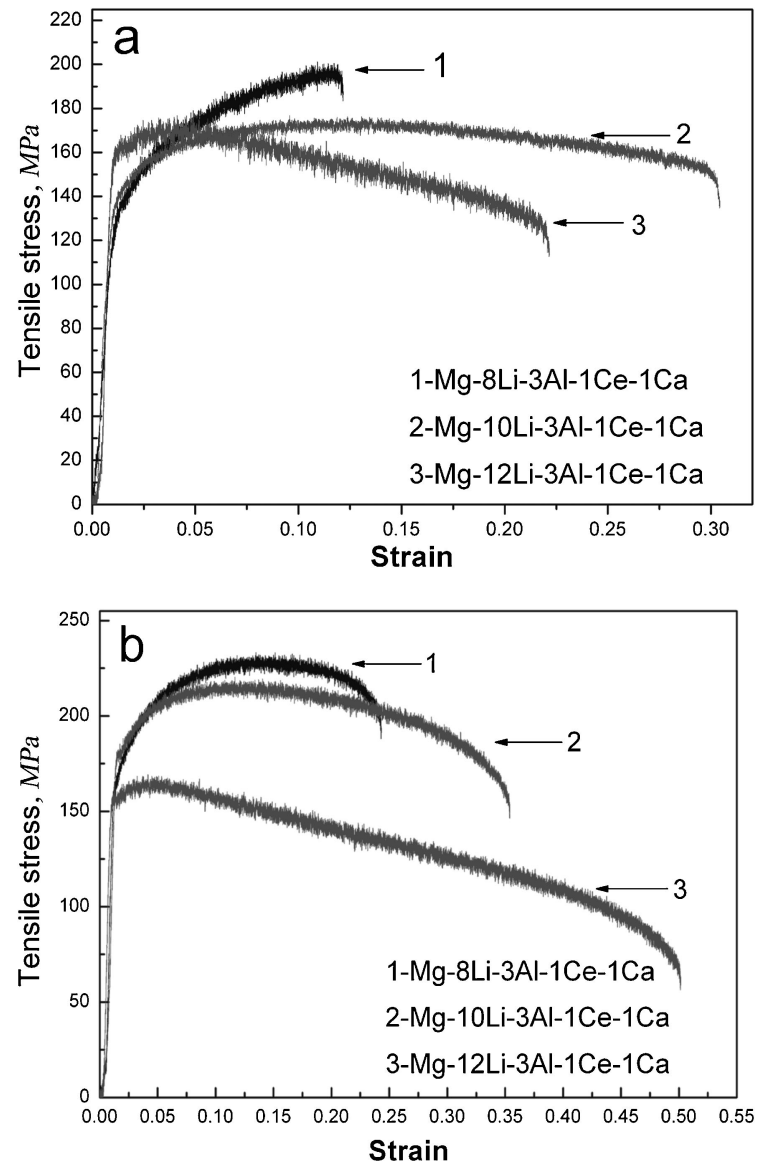

Fig. 7 Tensile properties of the as-cast $\mathrm{Mg}-\mathrm{Li}$ alloy (a) and the extruded Mg-Li alloy (b).

YS: $36 \%$ ) and $\mathrm{Mg}-8.15 \mathrm{Li}-3.07 \mathrm{Al}-1.12 \mathrm{Ce}-0.72 \mathrm{Ca}$ (UTS: $24 \%$, YS: $46 \%$ ) alloys have improved after extruding process (see Fig. 7(b)). Although the grains have been refined, neither the tensile strength nor the yield strength of the $\mathrm{Mg}$ 10.54Li-3.54Al-1.23Ce-0.94Ca alloy changes. It is likely that small pieces of $\alpha$ phases located at $\beta$ grain boundaries. Therefore, it is suggested that $\alpha$ phase may be an obstacle dislocation movement but not co-deformation media in $\beta$ phase alloys. From the above consideration, the special mechanism for deformation in the Mg-10.54Li-3.54-Al$1.23 \mathrm{Ce}-0.94 \mathrm{Ca}$ alloy may be a special grain boundary sliding and the result can be illustrated as shown in Fig. 8. Elongations of all alloys have increased. Serrated flow occurs in all of three alloys, especially in the $\mathrm{Mg}-10.54 \mathrm{Li}-$ 3.54Al-1.23Ce-0.94Ca alloy. This phenomenon can be interpreted through the competition between dynamic strain aging (DSA) of solute atoms and shearing of precipitates by dislocations. ${ }^{16)}$ In the deformation proceeding, piling up of dislocation shear the fine particles of $\mathrm{MgAl}_{2} \mathrm{Li}$ and then the stress concentration will be relaxed temporarily. The repeated shearing result in successive stress drops and the jerky appearance occurred. Hence the flow stress kept at a fixed value with the slowly reducing of tension specimen cross sectional area. This is the reason of work-softening in the engineering stress curves in Fig. 7.

In extruding process, dynamic recrystallization occurs and dislocation density decreases. The main strengthening effect of the two alloys is grain size. Previous works ${ }^{12)}$ have 

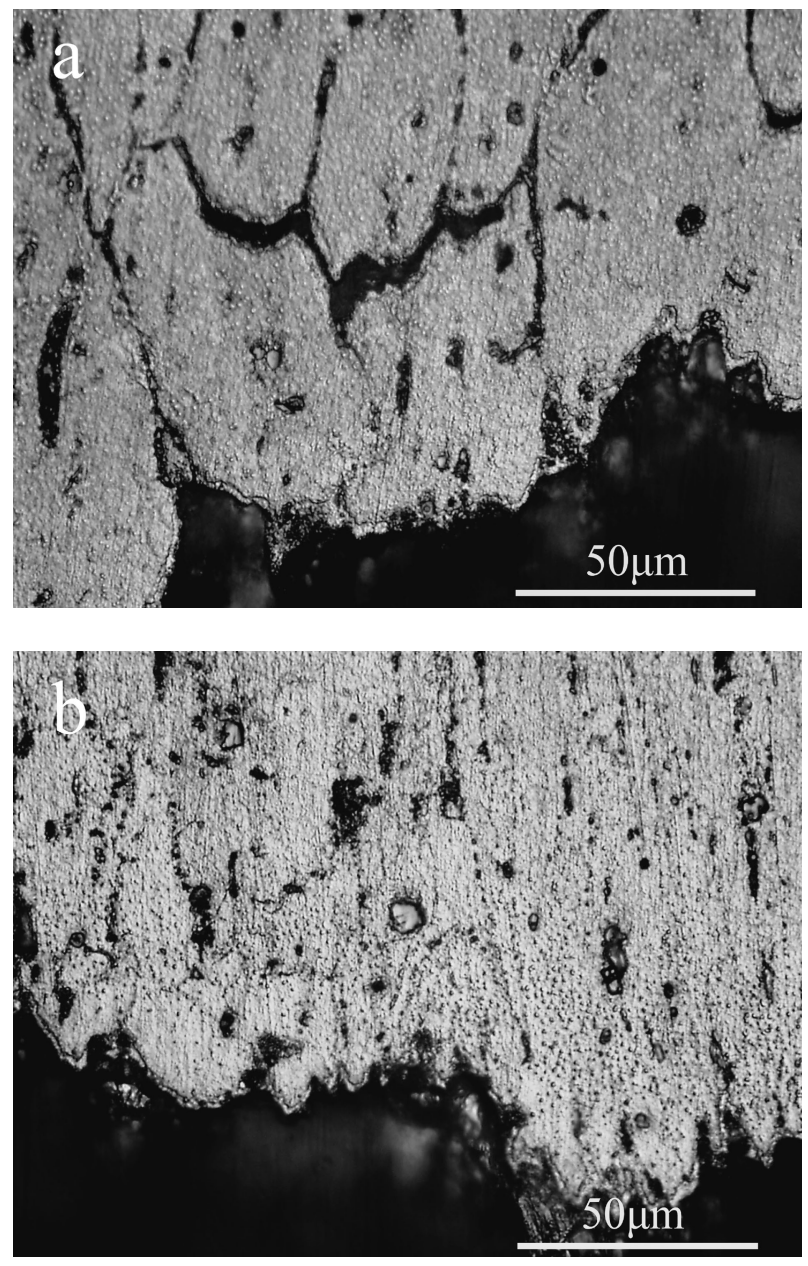

Fig. 8 Microstructures of Mg-12Li-3Al-1Ce-1Ca alloy near the tensile fractured surfaces: (a) as-cast specimen (b) extruded specimen.

indicated that the sizes of the all the three extruded specimens are within the range from $10 \mu \mathrm{m}$ to $15 \mu \mathrm{m}$. Some fine and equiaxed grains are less than $10 \mu \mathrm{m}$ for the reason of dynamic recovery and recrystallization in extruded specimens. The fine recrystallized grains increase the grain boundary area. Due to the restrictions of recrystallized grain boundaries, dislocation movement becomes more difficult and the strength increases. The lattice distortion bring about by broken dispersed compounds has also attributed to the strength improvement.

\section{Conclusions}

(1) In as-cast specimens of $\mathrm{Mg}-6.86 \mathrm{Li}-3.02 \mathrm{Al}-1.12 \mathrm{Ce}-$ $0.7 \mathrm{Ca}$ and $\mathrm{Mg}-8.15 \mathrm{Li}-3.07-\mathrm{Al}-1.12 \mathrm{Ce}-0.72 \mathrm{Ca}$ alloys, the microstructures are composed of $\alpha(\mathrm{Mg})$ phase, $\beta(\mathrm{Li})$ phase, rod-like and bulk $\mathrm{Al}_{2} \mathrm{Ce}$ compound and $\mathrm{Al}_{2} \mathrm{Ca}$ compound. In addition, in the $\mathrm{Mg}-10.54 \mathrm{Li}-3.54 \mathrm{Al}-1.23 \mathrm{Ce}-0.94 \mathrm{Ca}$, the microstructures contain $\alpha(\mathrm{Mg})+\beta(\mathrm{Li})$ eutectic region, rodlike and bulk $\mathrm{Al}_{2} \mathrm{Ce}$ compound and $\mathrm{Al}_{2} \mathrm{Ca}$ compound. $\mathrm{Al}_{2}(\mathrm{Ce}, \mathrm{Ca})$ compound is found in all of three alloys and its orientation relationship with the magnesium matrix is: $[\overline{1} 12] / /[\overline{7} \overline{2} \overline{5} 3] \alpha,(1 \overline{1} 1) / /(01 \overline{1} \overline{1}) \alpha$.

(2) After extruding progress, both $\alpha(\mathrm{Mg})$ phase and $\beta$ (Li) phase are refined. The bulk and rod-like compounds break up into short rods and fine clumps. The $\beta$ (Li) phase becomes long strip under the compression stress in the extruding direction. $\alpha(\mathrm{Mg})$ phase in eutectic structure shows up and assemble in the form of white long strip along the extruding direction. $\{0001\}\langle 11 \overline{2} 0\rangle$ slip system is activated in the extruding progress.

(3) The effect of extruding process on the tensile properties was observed. The refined compounds and the recrystallization after extruding process might result in the strengthening effect. The extruded Mg-8.15Li-3.07Al-1.12Ce-0.72Ca alloy presents good mechanical properties.

\section{Acknowledgements}

This study is supported by the national science and technology supporting program of China (No.: 2006BA104B041; No.: 2006BAE04B07-03), the Science and Technology Supporting Project of Changchun City (No.: 2007KZ05), and the "985 Project" of Jilin University. The project is financially supported by the Key Laboratory of Superlight Material and Surface Technology (Harbin Engineering University), Ministry of Education.

\section{REFERENCES}

1) J. H. Jackson, P. D. Frost, A. C. Loonam, L. W. Eastwood and C. H. Lorig: Trans. Metall. AIME 185 (1949) 149-168.

2) R. S. Busk, D. L. Leman and J. J. Casey: Trans. Metall. AIME 188 (1950) 945-951.

3) M. Furui, C. Xu, T. Aida, M. Inoue, H. Anada and T. G. Langdon: Mater. Sci. Eng. A 410-411 (2005) 439-422.

4) R. Z. Wu, Z. K. Qu and M. L. Zhang: Mater. Sci. Eng. A 516 (2009) 96-99.

5) T. Wang, M. L. Zhang and R. Z. Wu: Mater. Lett. 62 (2008) 18461848.

6) A. Sanschagrin, R. Tremblay, R. Angers and D. Dube: Mater. Sci. Eng. A 220 (1996) 67-77.

7) G. S. Song and M. V. Kral: Mater. Charact. 54 (2005) 279-286.

8) M. Sakamoto, S. Akiyama and K. Ogi: J. Mater. Sci. Lett. 16 (1997) 1048.

9) G. S. Song, M. S. Staiger and M. V. Kral: Magnesium Technology 2003, TMS Annual Meeting, San Diego, CA, USA, Mar. 2-6, (2003) pp. 77-80.

10) G. H. Wu, Y. Fan, H. T. Gao, C. Q. Zhai and Y. P. Zhu: Mater. Sci. Eng. A 408 (2005) 255-263.

11) X. Tian, L. M. Wang, J. L. Wang, Y. B. Liu, J. An and Z. Y. Cao: J. Alloy. Compd. 465 (2008) 412-416.

12) L. R. Cheng, Z. Y. Cao, R. Z. Wu and M. L. Zhang: IJMPB 20 (2009) 920-926.

13) M. V. Kral, B. C. Muddle and J. F. Nie: Mater. Sci. Eng. A 460-461 (2007) 227-232.

14) A.-B. Ma, Y. Nishida, N. Saito, I. Shigematsu and S.-W. Lim: Mater. Sci. Technol. 19 (2003) 1642-1647.

15) Z. Trojanova, Z. Drozd, P. Lukac and F. Chmelik: Mater. Sci. Eng. A 410-411 (2005) 148-151.

16) C. Wang, Y. B. Xu and E. H. Han: Mater. Lett. 60 (2006) 2941-2944. 